\title{
ON THE SIMPLIFIED DESIGN METHOD FOR INTERMEDIATE DIAPHRAGMS IN STEEL BOX GIRDER BRIDGES
}

\author{
By Teruhiko YODA*, Hiroyuki SHIMIZU** \\ and Masaharu HIRASHIMA***
}

\begin{abstract}
The design of steel box girder bridges under unsymmetrically placed live loads involves consideration of intermediate diaphragms that are required to limit crosssectional deformation and distortional normal stresses. In this paper, the required spacing and stiffness of such intermediate diaphragms are examined by performing a parametric study based on Beam Analogy.

The results of the present parametric study yield a series of simplified design procedure that accounts for estimating diaphragm spacing and stiffness that are required to limit not only distortional stresses but also cross-sectional deformation.
\end{abstract}

\section{INTRODUCTION}

Steel box girder bridges have intermediate diaphragms for the purpose of limitting cross sectional deformation and distortional stresses ${ }^{1)}$. Some papers on the design procedure for intermediate diaphragms in steel box girder bridges have been submitted by Merrison Committee ${ }^{2)}$, Sakai and $\mathrm{Nagai}^{3)}$, Heins ${ }^{4)}$, Nakai and Murayama ${ }^{5)}$, Komatsu and $\mathrm{Nagai}^{6}{ }^{6}$. They have refered to design formula, and it seems to be established in the case of the straight box girders.

The purpose of this paper is to develop a simplified design procedure for intermediate diaphragms on the basis of Beam Analogy ${ }^{3)}$, which can satisfy the limitation of both distortional stress and cross-sectional deformation. The present design procedure is efficient in that designers can determine optionally required spacing and stiffness of intermediate diaphragms. The characteristics of the present design procedure is that appropriate spacing is specified between the longest spacing enough to restrict distortional stress within allowable stress and the critical spacing enough to keep the validity of Beam Analogy.

\section{APPROXIMATE CALCULATION DUE TO BEAM ANALOGY}

Governing equation for cross-sectional deformation is written $a^{3)}$, in terms of angular distortion $V$ $E I_{w} V^{\prime \prime \prime \prime}-p_{v}=0$

where $E$ : Young's modulus, $I_{w}$ : warping constant for cross-sectional deformation, $p_{v}:$ distributed torsional load equilibrated by cross-sectional deformation, and a prime ()$^{\prime}$ 'denotes differentiation with

* Member of JSCE Dr. of Eng., Associate Professor, Dept. of Civil Engineering, Waseda University (3-4-1 Ōkubo Shinjuku-ku Tokyo)

** Member of JSCE M. of Eng., Chiyoda Chemical Engineering \& Construction Co., LTD. (formerly Graduate Student of Waseda University)

*** Member of JSCE Dr. of Eng., Professor, Dept. of Civil Engineering, Waseda University 


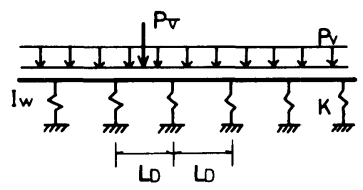

Fig. 1 Beam Analogy.

respect to longitudinal coordinate.

The distortional phenomenon can be represented by a differential equation identical in form to that for beams on elastic supports as shown in Fig. 1. The effect of intermediate diaphragm spacing and stiffness on the box girder behavior is determined by evaluating the corresponding support spacing and support stiffness for the analytical model called Beam

Analogy, maximum distortional stress $\sigma_{D W}$ equilibrated by cross-sectional deformation has the form ${ }^{3)}$

$$
\sigma_{D w}=\frac{M_{w}}{I_{w}} \phi
$$

where $M_{w}$ : maximum warping moment and $\phi:$ warping mode due to cross-sectional deformation.

Consider the procedure of determining required spacing and stiffness of the equally-spaced intermediate diaphragms from Eqs. (1) and (2) by using the conventional stiffness parameter ${ }^{3}$ :

$$
\gamma=\frac{K L_{D}^{3}}{E I_{w}}
$$

where $K$ : stiffness of intermediate diaphragms, $L_{D}$ : spacing of intermediate diaphragms.

Normalizing the maximum warping moment for concentrated and distributed torsional loads yields the relationships between the stiffness parameter and the maximum warping moment in accordance with the number of equally-spaced diaphragms as shown in Figs.2,3, in which the maximum warping moment $M_{w}$ is determined from putting the end conditions $V=0 ; V^{\prime \prime}=0$ and computing the absolute maximum warping moment which depends on the parameter $\gamma$ as well as the load distribution. In Figs.2,3, it is shown that the maximum warping moment converges when the number of diaphragms is more than six. On the basis of available data of box girder bridges, the maximum warping moments due to concentrated and distributed torsional loads may be expressed as, under the limitation of $0<1 / \gamma \leqq 2$,

$$
\begin{aligned}
& M_{w c} /\left(P_{v} L_{D}\right)=0.21 \sqrt{1 / \gamma+0.05}+0.18 \\
& M_{w u} /\left(p_{v} L_{D}^{2}\right)=0.34 \sqrt{1 / \gamma+0.05} \ldots \ldots \ldots \ldots
\end{aligned}
$$

In view of Eqs. (2),(4),(5), distortional stress

$$
\sigma_{D W}=\frac{0.18 P_{v} L_{D}+0.21 P_{v} L_{D} \sqrt{1 / \gamma+0.05}+0.34 p_{v} L_{D}^{2} \sqrt{1 / \gamma+0.05}}{I_{w}} \phi
$$

In the case of designing, the distortional stress is required to be less than the allowable stress $\sigma_{D \text { wal }}$ (for example, $\sigma_{D w a l}=50 \mathrm{Kg} / \mathrm{cm}^{2}\left(4.9 \mathrm{MN} / \mathrm{m}^{2}\right)$ ) such as

$$
\sigma_{D w} \leqq \sigma_{D w a l}
$$

Hence, the required stiffness of diaphragms can be determined from Eqs. (6) and (7)

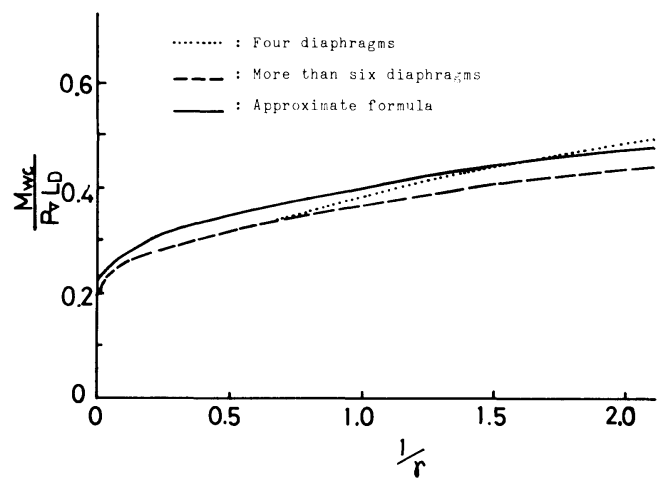

Fig. 2 Maximum Warping Moment due to Concentrated Torsional Load.

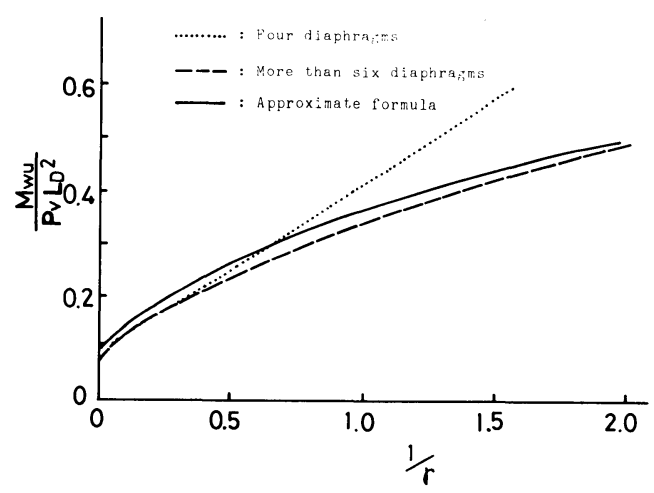

Fig. 3 Maximum Warping Moment due to Uniform Torsional Load. 


$$
K=\frac{E I_{w}}{L_{D}^{3}}\left\{\frac{\left(0.21 P_{v} L_{D}+0.34 p_{v} L_{D}^{2}\right)^{2}}{\left(\sigma_{D w a l} I_{w} / \phi-0.18 P_{v} L_{D}\right)^{2}-0.05\left(0.21 P_{v} L_{D}+0.34 p_{v} L_{D}^{2}\right)^{2}}\right\}
$$

In view of Eq. (8), the spacing of diaphragms becomes infinite under the condition of Eq. (7), which leads to

$$
L_{D \max }=\frac{-0.227 P_{v}+\sqrt{\left(0.227 P_{v}\right)^{2}+0.304 p_{v} \sigma_{D w a l} I_{w} / \phi}}{0.152 p_{v}}
$$

This means that spacing more than $L_{D \max }$ causes the excess of distortional stress.

In addition, the validity of Eqs. (4) and (5) is restricted to the aforementioned inequality $0<1 / \gamma \leqq 2$, so that the critical diaphragm spacing $L_{D C r}$ is determined from Eq. (8) by putting $1 / \gamma=2$

$$
L_{D c r}=\frac{-0.481 P_{v}+\sqrt{\left(0.481 P_{v}\right)^{2}+1.923 p_{v} \sigma_{D w a l} I_{w} / \phi}}{0.974 p_{v}}
$$

It follows also from the fact that the values of $M_{w c} /\left(P_{v} L_{D}\right)$ and $M_{w u} /\left(p_{v} L_{D}^{2}\right)$ fluctuate greatly according to the number of diaphragms in the case of $1 / \gamma>2$. Accordingly, in the case of $L_{D}<L_{D c r}$, the required stiffness of diaphragms is computed from

$$
K_{c r}=\frac{E I_{w} \gamma_{c r}}{L_{D}^{3}} \quad\left(\gamma_{c r}=0.5\right)
$$

In the next place, consider the way how to limit angular distortion in a suitable value. The normalizing maximum angular distortion $\mathrm{V}$ due to concentrated and distributed torsional loads will be obtained in an analogous way to the determination of warping moments. Therefore, the maximum angular distortion Vc due to concentrated torsional load and the maximum angular distortion Vu due to distributed torsional load can be predicted accurately enough for design purposes as follows,

$$
\begin{aligned}
& V_{c}=\frac{P_{v} L_{D}^{3}}{E I_{w}}\left(0.03+0.38 \gamma^{-\frac{4}{5}}\right) \\
& V_{u}=\frac{p_{v} L_{D}^{4}}{E I_{w}}\left(0.05+\gamma^{-1}\right) \ldots \ldots
\end{aligned}
$$

The required spacing and stiffness of diaphragms are determined so as to satisfy the inequality

$$
V=V_{c}+V_{u} \leqq V_{a l}
$$

Where $V_{a l}$ : allowable angular distortion which can be assumed according to the required accuracy for fabrication or the allowable plate bending stress $\sigma_{B a l}$.

\section{PROPOSAL OF A SIMPLIFIED DE- SIGN PROCEDURE}

On the basis of the foregoing calculations, the flow chart of design procedure will be described as shown in Fig.4.

In the first place, maximum diaphragm spacing $L_{\text {Dmax }}$ (due to Eq.(9)) and critical diaphragm spacing $L_{D c r}$ (due to Eq.(10)) are uniquely determined from the assumed value of $\phi, I_{w}, P_{v}, p_{v}, \sigma_{D w a l}$. In consideration of fabrication, transportation, erection of box girder bridges, the diaphragm spacing $L_{D}$ are chosen, if possible so as to satisfy the following condition:

$$
L_{D c r} \leqq L_{D}<L_{D \max }
$$

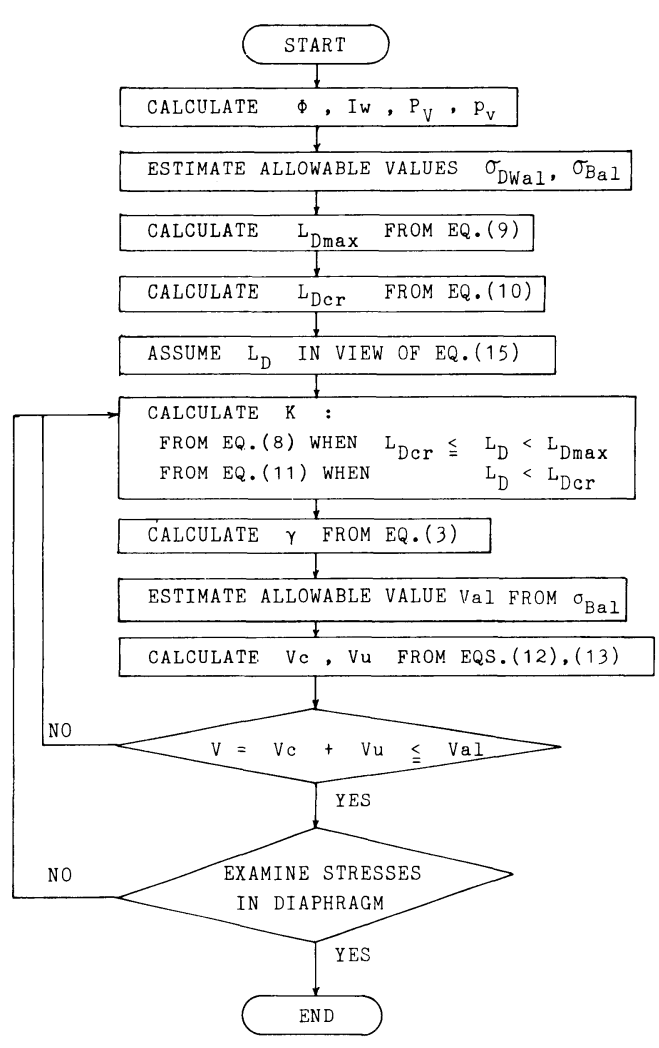

Fig. 4 Design Procedure for Diaphragms. 
Table 1 Comparative example.

\begin{tabular}{l|c|c|c}
\hline & Reference 6) (BEF Analogy) & \multicolumn{2}{|c}{ Present Method (Beam Analogy) } \\
\hline Allowable Warping Stress $\sigma_{\text {DWal }}$ & $42 \mathrm{Kg} / \mathrm{cm}^{2}\left(4.12 \mathrm{MN} / \mathrm{m}^{2}\right)$ & $42 \mathrm{Kg} / \mathrm{cm}^{2}\left(4.12 \mathrm{MN} / \mathrm{m}^{2}\right)$ & $42 \mathrm{Kg} / \mathrm{cm}^{2}\left(4.12 \mathrm{MN} / \mathrm{m}^{2}\right)$ \\
\hline Maximum Warping Stress $\sigma_{\mathrm{DW}}$ & $38 \mathrm{Kg} / \mathrm{cm}^{2}\left(3.72 \mathrm{MN} / \mathrm{m}^{2}\right)$ & $42 \mathrm{Kg} / \mathrm{cm}^{2}\left(4.12 \mathrm{MN} / \mathrm{m}^{2}\right)$ & $42 \mathrm{Kg} / \mathrm{cm}^{2}\left(4.12 \mathrm{MN} / \mathrm{m}^{2}\right)$ \\
\hline Diaphragm Spacing $\mathrm{L}_{\mathrm{D}}$ & $6 \mathrm{~m}$ & $6 \mathrm{~m}$ & $8 \mathrm{~m}$ \\
\hline Required Stiffness K & $1.156 \times 10^{11} \mathrm{Kg} \cdot \mathrm{cm}(11.33 \mathrm{GN} \cdot \mathrm{m})$ & $1.33 \times 10^{11} \mathrm{Kg} \cdot \mathrm{cm}(13.0 \mathrm{GN} \cdot \mathrm{m})$ & $1.96 \times 10^{11} \mathrm{Kg} \cdot \mathrm{cm}(19.2 \mathrm{GN} \cdot \mathrm{m})$ \\
\hline Allowable Angular Distortion $\mathrm{V}_{\text {al }}$ & $-10.01 \times 10^{-5} \mathrm{rad}$ & $10^{-3} \mathrm{rad}$ & $10^{-3} \mathrm{rad}$ \\
\hline Maximum Angular Distortion V & $10.66 \times 10^{-5} \mathrm{rad}$ & $9.46 \times 10^{-5} \mathrm{rad}$ \\
\hline
\end{tabular}

Then, the required stiffness $\mathrm{K}$ is computed from Eq.(8) or (11) depending on $L_{D}$.

Once the values $L_{D}$ and $\mathrm{K}$ are decided, stiffness parameter $\gamma$ can be obtained from Eq.(3). The angular distortion is examined by using Eqs.(12), (13), (14). If the calculated angular distortion exceeds the allowable value of $V_{a l}$, designers should decrease the diaphragm spacing $L_{D}$ or increase the diaphragm stiffness $\mathrm{K}$ in order to limit the angular distortion.

\section{EXAMPLE OF DESIGN CALCULATION}

The accuracy of the present simplified design procedure is explored by comparison with the results of Ref.(6) which is based on the BEF Analogy').

The basic data are $\phi=1.25 \times 10^{5} \mathrm{~cm}^{6}, I_{w}=1.654 \times 10^{13} \mathrm{~cm}^{6}, P_{v}=167.6 \mathrm{t} \cdot \mathrm{m}(1.642 \mathrm{MN} \cdot \mathrm{m}), p_{v}=10.06$ $\mathrm{t} \cdot \mathrm{m} / \mathrm{m}(98.59 \mathrm{KN} \cdot \mathrm{m} / \mathrm{m})$. If one assumes the allowable distortional stress as $\sigma_{D w a l}=42 \mathrm{Kg} / \mathrm{cm}^{2}(4.9 \mathrm{MN} /$ $\mathrm{m}^{2}$ ), the maximum diaphragm spacing becomes $L_{D \max }=11.8 \mathrm{~m}$ from Eq.(9) and the critical diaphragm spacing becomes $L_{D c r}=5.2 \mathrm{~m}$ from Eq. (10).

Hence, from Eq.(15), the diaphragm spacing can be determined as $L_{D}=6.0 \mathrm{~m}$. As a result, the stiffness of the diaphragm becomes $K=1.33 \times 10^{11} \mathrm{Kg} \cdot \mathrm{cm}(1.30 \mathrm{GN} \cdot \mathrm{m})$ from $\mathrm{Eq} .(8)$.

Moreover, if one assume the allowable angular distortion as $V_{a l}=10^{-3} \mathrm{rad}$ provisionally. The inequality for angular distortion is given by $V=V_{c}+V_{u}=9.66 \times 10^{-5}<10^{-3}$ where $V_{c}=4.93 \times 10^{-5}$ rad and $V_{u}$ $=4.74 \times 10^{-5} \mathrm{rad}$ are computed from Eqs. (12) and (13) respectively. It follows from this that the assumed spacing and stiffness of diaphragms satisfy the allowable angular distortion. The above numerical results are compared with those of Ref. (6) in Table 1.

As can be observed from Table 1, the present simplified design procedure seems to be appropriate. This statement is supported by the evidence of spacing and stiffness of existing diaphragms of box girder bridges.

Finally, the authors wish to express their deepest appreciation to Y. Kumagai, Mitsubishi Heavy Industries for the valuable suggestions.

\section{REFERENCES}

1) Japan Road Association: Design Handbook of Steel Highway Bridges, 1979.2 (In Japanese).

2) The subcommittee of Inquiry into the Basis of Design and Method of Erection of Steel Box Girder Bridges: Interium Design and Workmanship Rules, Her Majesty's Stationary Office, 1973.

3) Sakai, F. and Nagai, M.: A recommendation on the design of intermediate diaphragms in steel box girder bridges, Proc. of JSCE, No.261, pp.21 34, 1977 (In Japanese).

4) Heins, C.P.: Box girder bridge design - state of the art, AISC Engineering Journal, Fourth Quarter, 1978.

5) Nakai,M. and Murayama, Y.: Distortional stress analysis and design aid for horizontally curved box girder bridges with diaphragms, Proc. of JSCE, No.309, pp.25 39, 1981 (In Japanese).

6) Komatsu, S. and Nagai, M.: Study on a new design technique for intermediate diaphragms, Proc. of JSCE, No.326, pp.51 62, 1982 (In Japanese).

(Received August 13 1983) 